ARTICLE

https://doi.org/10.1038/s41467-019-12767-5

\title{
Quadruple bonding between iron and boron in the $\mathrm{BFe}(\mathrm{CO})_{3}{ }^{-}$complex
}

Chaoxian Chi (1) ${ }^{1,5}$, Jia-Qi Wang ${ }^{2,5}$, Han-Shi Hu ${ }^{2 \star}$, Yang-Yang Zhang ${ }^{2}$, Wan-Lu Li ${ }^{2}$, Luyan Meng ${ }^{1}$, Mingbiao Luo ${ }^{1}$, Mingfei Zhou (iD ${ }^{3 \star} \&$ Jun $\mathrm{Li}^{2,4 \star}$

While main group elements have four valence orbitals accessible for bonding, quadruple bonding to main group elements is extremely rare. Here we report that main group element boron is able to form quadruple bonding interactions with iron in the $\mathrm{BFe}(\mathrm{CO})_{3}{ }^{-}$anion complex, which has been revealed by quantum chemical investigation and identified by massselected infrared photodissociation spectroscopy in the gas phase. The complex is characterized to have a $\mathrm{B}-\mathrm{Fe}(\mathrm{CO})_{3}{ }^{-}$structure of $\mathrm{C}_{3 \mathrm{v}}$ symmetry and features a $\mathrm{B}$ - $\mathrm{Fe}$ bond distance that is much shorter than that expected for a triple bond. Various chemical bonding analyses indicate that the complex involves unprecedented $\mathrm{B} \equiv \mathrm{Fe}$ quadruple bonding interactions. Besides the common one electron-sharing $\sigma$ bond and two $\mathrm{Fe} \rightarrow \mathrm{B}$ dative $\pi$ bonds, there is an additional weak $B \rightarrow F e$ dative $\sigma$ bonding interaction. This finding of the new quadruple bonding indicates that there might exist a wide range of boron-metal complexes that contain such high multiplicity of chemical bonds.

\footnotetext{
${ }^{1}$ School of Chemistry, Biological and Materials Sciences, East China University of Technology, 330013 Nanchang, Jiangxi Province, China. ${ }^{2}$ Department of Chemistry \& Key Laboratory of Organic Optoelectronics and Molecular Engineering of Ministry of Education, Tsinghua University, 100084 Beijing, China. ${ }^{3}$ Department of Chemistry, Shanghai Key Laboratory of Molecular Catalysis and Innovative Materials, Fudan University, 200433 Shanghai, China.

${ }^{4}$ Department of Chemistry, Southern University of Science and Technology, 518055 Shenzhen, China. ${ }^{5}$ These authors contributed equally: Chaoxian Chi, Jia-

Qi Wang. *email: hshu@mail.tsinghua.edu.cn; mfzhou@fudan.edu.cn; junli@tsinghua.edu.cn
} 
C hemical bonding is among the most fundamental concepts in modern chemistry. Depending upon the availability of valence orbitals and electrons, an atom can form single or multiple covalent chemical bonds with neighboring atoms in forming stable compounds. Since the discovery of Re-Re quadruple bond in 1964 by Cotton and coworkers ${ }^{1,2}$, metal-metal multiple bonding with bond orders of four to six has been extensively explored for transition metals and actinides ${ }^{3-18}$. Main group elements of the periodic table may form single, double, and triple bonds between two atoms, that is, the maximum bond order can only be three as exemplified in alkyne. Triple bonds between two main group atoms are well established, and a large number of triple-bonded molecules are known ${ }^{19-26}$. As main group elements have $n s n p$ four valence orbitals accessible for bonding, it has been speculated that a further extension to bond order of four for main group elements should in principle be possible. Diatomic $\mathrm{C}_{2}$ and its isoelectronic molecules $\mathrm{CB}^{-}, \mathrm{BN}$, and $\mathrm{CN}^{+}$each having eight valence electrons were claimed to be quadruple-bonded molecules, comprising not only one $\sigma$ - and two $\pi$-bonds, but also one weak 'inverted' bond ${ }^{27}$. However, this quadruple bond assignment has been debated, which has stimulated hot discussion ${ }^{28-30}$. Quadruple bonding of carbon to uranium with rich valence shell (sdf) has been reported to exist in the triatomic uranium carbide oxide molecule CUO and related species, due to availability of both $2 p$ and unhybridized $2 s$ orbitals of carbon ${ }^{31,32}$. Besides the ubiquitous one $\sigma$ - and two $\pi$-bonds, a non-negligible, albeit weak, rearward $\sigma$-bond was characterized to exist between $\mathrm{C}$ and $\mathrm{U}$ atoms.

As an electron-deficient atom, boron prefers to form delocalized multicenter bonds and resists multiple bonding in general. However, boron is capable of forming homoatomic B-B double and triple bonds as well as multiple bonds to other elements. In 2002 , one of us reported the first $\mathrm{B} \equiv \mathrm{B}$ triple bond in $(\mathrm{OC}) \mathrm{BB}(\mathrm{CO})$ formed in a low temperature argon matrix ${ }^{20}$. This work was followed by Wang and coworkers on the gas-phase characterization of the isoelectronic, $\mathrm{B} \equiv \mathrm{B}$ triple-bonded dianionic molecule $[(\mathrm{OB}) \mathrm{BB}(\mathrm{BO})]^{2-21}$. These reports were accompanied by a flurry of theoretical studies exploring a range of donors for stabilizing the triple-bonded $\mathrm{B}_{2}$ unit $^{33-35}$. The first chemical compound containing a $\mathrm{B} \equiv \mathrm{B}$ triple bond that is stable at ambient temperature was synthesized in 2012 by Braunschweig and coworkers and was confirmed by X-ray crystallography 22,23 . Boron can also form multiple bonds with metal atoms, and a number of complexes featuring transition metal-boron double bond have been characterized ${ }^{36-38}$. However, boron-metal multiple bonding with bond orders above two is elusive, although boron-metal triple bonds were found in nominal $\mathrm{MB}$ diatomics ${ }^{39,40}$. Only a bismuth-boron cluster anion, $\mathrm{BiB}(\mathrm{BO})^{-}$ was formed in the gas phase, which was characterized by photoelectron spectroscopy and theoretical calculations to contain a bismuth-boron triple bond ${ }^{41}$. Complexes featuring borontransition metal quadruple bonding interactions are currently unidentified.

Here we report that main group element boron is able to form quadruple bonding interactions with transition metal iron in the $\mathrm{BFe}(\mathrm{CO})_{3}{ }^{-}$anion complex, which is found through advanced quantum chemical calculations and is experimentally generated in the gas phase and characterized by mass-selected infrared photodissociation spectroscopy.

\section{Results}

Mass spectra. The iron-boron heteronuclear carbonyl anion complexes were generated in the gas phase using a pulsed laser vaporization/supersonic-expansion ion source ${ }^{42}$. The anion complex was mass-selected by its flight time and was studied by infrared photodissociation spectroscopy in the carbonyl stretching vibrational frequency region (see Methods). The mass spectrum in the $\mathrm{m} / \mathrm{z}$ range of $100-250$ obtained by pulsed laser vaporization of a boron-10 depleted target in expansions of helium gas seeded with $7 \% \mathrm{CO}$ is shown in Fig. 1. The spectrum is dominated by the peak at $m / z=168$ that can be assigned to the $\mathrm{Fe}(\mathrm{CO})_{4}{ }^{-}$anion, which is a common species observed in the experiments using the carbon monoxide samples containing trace of iron carbonyl impurity. Besides the most intense $\mathrm{Fe}(\mathrm{CO})_{4}{ }^{-}$ anion peak, the next most intense peaks are observed at $\mathrm{m} / z=$ 151 and $m / z=207$, which can be assigned to the ${ }^{11} \mathrm{BFe}(\mathrm{CO})_{3}{ }^{-}$ and ${ }^{11} \mathrm{BFe}(\mathrm{CO})_{5}{ }^{-}$anions, respectively. Similar experiments with natural abundance boron and boron-10 enriched targets were also performed, and the mass spectra are shown in Supplementary Fig. 1. Additional experiments using a ${ }^{13} \mathrm{C}$-substituted $\mathrm{CO}$ sample were performed to confirm that the observed species at $m / z=151$ is due to ${ }^{11} \mathrm{BFe}(\mathrm{CO})_{3}{ }^{-}$rather than the equal mass ${ }^{11} \mathrm{~B}(\mathrm{CO})_{5}{ }^{-}$or ${ }^{11} \mathrm{BFe}_{2} \mathrm{CO}$. A mixed target involving boron-10 depleted boron and iron was used to incorporate iron atoms into the system, as the ${ }^{13} \mathrm{C}$-substituted $\mathrm{CO}$ sample does not involve any iron carbonyl impurity. These experiments provide conclusive identification of the $\mathrm{BFe}(\mathrm{CO})_{3}{ }^{-}$anion complexes.

Infrared photodissociation spectra. The $\mathrm{BFe}(\mathrm{CO})_{3}{ }^{-}$anion was selected for infrared photodissociation by a tunable IR laser beam. The anion photo-dissociates via the loss of one CO ligand when the IR laser is on resonance with the carbonyl stretching fundamentals of the anion. The dissociation is observed only under focused infrared light irradiation with very low efficiency. The parent anions were depleted by less than 3\% at the laser pulse energy of $\sim 0.8 \mathrm{~mJ}$ per pulse at $1841 \mathrm{~cm}^{-1}$. Such low dissociation efficiency implies that the $\mathrm{BFe}(\mathrm{CO})_{3}{ }^{-}$anion is a strongly bonded species and the dissociation is due to a multiphoton process. The IR photodissociation spectrum of ${ }^{11} \mathrm{BFe}(\mathrm{CO})_{3}{ }^{-}$obtained by monitoring the fragment ion yield as a function of the dissociation IR laser wavelength in the carbonyl stretching frequency region is shown in Fig. 2. The spectrum contains only two bands centered at 1841 and $1911 \mathrm{~cm}^{-1}$. The observation of only two carbonyl stretching bands suggests that the anion complex should have $\mathrm{C}_{3 \mathrm{v}}$ symmetry with all the three carbonyl ligands bonded to the same center. The bands are quite broad due to power broadening and/or the involvement of hot anions, as the

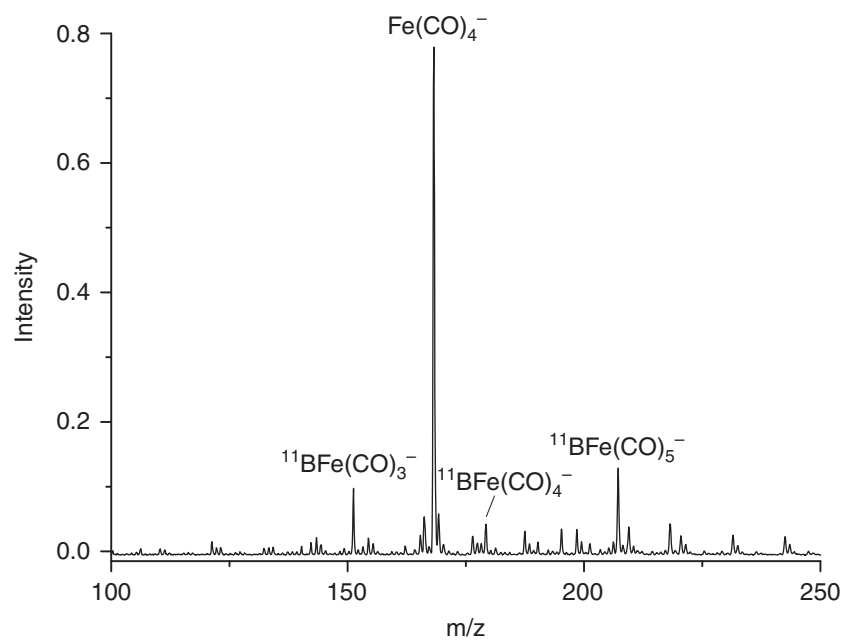

Fig. 1 Mass spectrum of the boron-iron carbonyl anion complexes. The complexes are formed by pulsed laser vaporization of a boron-10 depleted target in an expansion of helium seeded by $7 \%$ carbon monoxide with trace of iron carbonyl impurity 


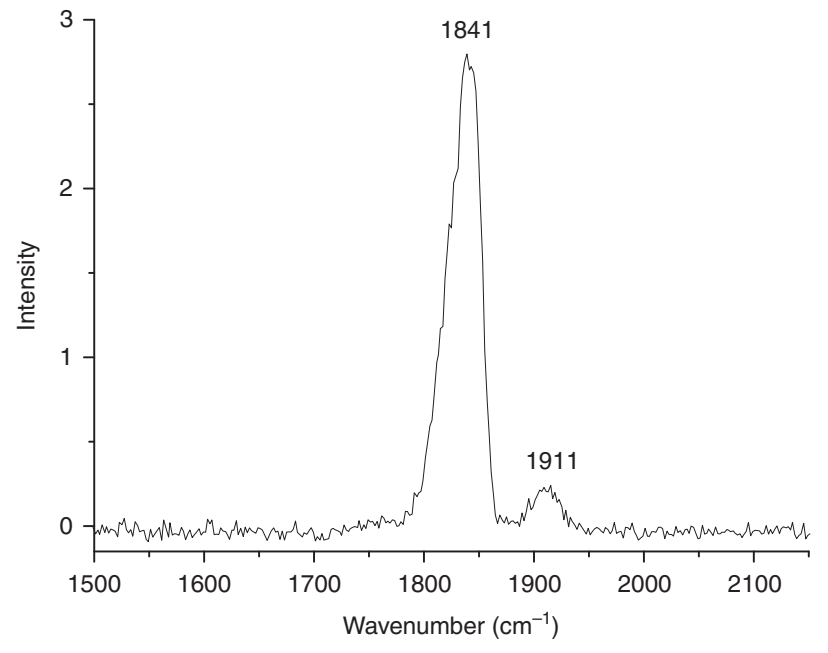

Fig. 2 Infrared photodissociation spectrum of the ${ }^{11} \mathrm{BFe}(\mathrm{CO})_{3}{ }^{-}$anion complex. The spectrum is measured in the carbonyl stretching frequency region by monitoring the $\mathrm{CO}$ photodissociation channel. Intensity is shown as the yield of fragmentation ion normalized to the parent ion signal in percentage

dissociation is a multiphoton process. The spectra of the ${ }^{10} \mathrm{BFe}$ $(\mathrm{CO})_{3}{ }^{-}$and ${ }^{11} \mathrm{BFe}\left({ }^{13} \mathrm{CO}\right)_{3}{ }^{-}$isotopomers are also recorded as shown in Supplementary Fig. 2. The ${ }^{11} \mathrm{BFe}\left({ }^{13} \mathrm{CO}\right)_{3}{ }^{-}$spectrum shows two bands at 1797 and $1859 \mathrm{~cm}^{-1}$. The isotopic shifts are appropriate for carbonyl stretching vibrations. The band positions of ${ }^{10} \mathrm{BFe}(\mathrm{CO})_{3}{ }^{-}$are only slightly blue-shifted from those of ${ }^{11} \mathrm{BFe}(\mathrm{CO})_{3}{ }^{-}$, indicating that the two observed modes are pure carbonyl stretching vibrations with negligible involvement of the boron atom. This observation also indicates that the three carbonyl ligands are coordinated on the iron center. Accordingly, the experimentally observed $\mathrm{BFe}(\mathrm{CO})_{3}{ }^{-}$anion should have a $\mathrm{B}-\mathrm{Fe}$ bonded $\mathrm{B}-\mathrm{Fe}(\mathrm{CO})_{3}{ }^{-}$structure with $\mathrm{C}_{3 \mathrm{v}}$ symmetry. The IR photodissociation spectra of the $\mathrm{Fe}(\mathrm{CO})_{4}{ }^{-}, \mathrm{BFe}(\mathrm{CO})_{4}{ }^{-}$, and $\mathrm{BFe}$ $(\mathrm{CO})_{5}{ }^{-}$anions are also recorded as shown in Supplementary Figs. $3-5$. The IR spectrum of $\mathrm{BFe}(\mathrm{CO})_{3}{ }^{-}$is quite different to those of the $\mathrm{Fe}(\mathrm{CO})_{4}{ }^{-}, \mathrm{BFe}(\mathrm{CO})_{4}{ }^{-}$and $\mathrm{BFe}(\mathrm{CO})_{5}{ }^{-}$anions, implying different structures and bonding patterns in these anion complexes.

Theoretical results. Quantum chemical calculations with density functional theory (DFT) and wavefunction theory (WFT) (see Methods) on the $\mathrm{BFe}(\mathrm{CO})_{3}{ }^{-}$complex and the other species observed reveal that the $\mathrm{BFe}(\mathrm{CO})_{3}{ }^{-}$complex is rather stable and has quadruple bonding interactions between boron and iron. The $\mathrm{B}-\mathrm{Fe}$ bonded $C_{3 \mathrm{v}}$ structure with all the carbonyl ligands coordinated to the Fe center was predicted to have a closed-shell singlet ground state as shown in Supplementary Table 1. The other isomers with one or two $\mathrm{CO}$ ligands bonded to the boron center, $(\mathrm{OC}) \mathrm{BFe}(\mathrm{CO})_{2}{ }^{-}$and $(\mathrm{OC})_{2} \mathrm{BFe}(\mathrm{CO})^{-}$were predicted to have triplet electronic ground states. The high-level ab initio DLPNO$\operatorname{CCSD}(\mathrm{T})$ calculations predicted that the $\mathrm{C}_{3 \mathrm{v}} \mathrm{BFe}(\mathrm{CO})_{3}{ }^{-}$isomer is more stable than the $(\mathrm{OC})_{2} \mathrm{BFe}(\mathrm{CO})^{-}$and $(\mathrm{OC}) \mathrm{BFe}(\mathrm{CO})_{2}{ }^{-}$ structures by 27.8 and $42.5 \mathrm{kcal} \mathrm{mol}^{-1}$, respectively. The calculated infrared spectra of the $\mathrm{BFe}(\mathrm{CO})_{3}{ }^{-}$, $(\mathrm{OC}) \mathrm{BFe}(\mathrm{CO})_{2}{ }^{-}$, and $(\mathrm{OC})_{2} \mathrm{BFe}(\mathrm{CO})^{-}$structures are compared with the experimental spectrum in Supplementary Fig. 6. The simulated spectrum of the most stable $\mathrm{C}_{3 \mathrm{v}} \mathrm{BFe}(\mathrm{CO})_{3}{ }^{-}$structure is consistent with the experimental spectrum. Although the main experimental band is quite broad with a full width at half-maximum (fwhm) of $\sim 35 \mathrm{~cm}^{-1}$, the high-lying $(\mathrm{OC})_{2} \mathrm{BFe}(\mathrm{CO})^{-}$and $(\mathrm{OC}) \mathrm{BFe}(\mathrm{CO})_{2}{ }^{-}$isomers are unlikely presented in the experiment because they are

\begin{tabular}{|c|c|c|c|c|}
\hline & \multicolumn{2}{|l|}{ sym. str. } & \multicolumn{2}{|l|}{ asym. str. } \\
\hline & $\begin{array}{l}{ }^{11} \mathrm{BFe} \\
\left({ }^{12} \mathrm{CO}\right)_{3}{ }^{-}\end{array}$ & $\begin{array}{l}{ }^{11} \mathrm{BFe} \\
\left({ }^{13} \mathrm{CO}\right)_{3}{ }^{-} \\
\end{array}$ & $\begin{array}{l}{ }^{11} \mathrm{BFe} \\
\left({ }^{12} \mathrm{CO}\right)_{3}{ }^{-} \\
\end{array}$ & $\begin{array}{l}{ }^{11} \mathrm{BFe} \\
\left({ }^{13} \mathrm{CO}\right)_{3}{ }^{-} \\
\end{array}$ \\
\hline PBE & 1929 (227) & 1881 (219) & $1860(1384)$ & 1816 (1313) \\
\hline B3LYPa & 1935 (308) & 1889 (289) & 1859 (1748) & $1817(1662)$ \\
\hline $\begin{array}{l}\text { M06- } \\
2 X^{a}\end{array}$ & 1966 (292) & 1918 (276) & 1847 (2177) & 1805 (2066) \\
\hline Exptl. & 1911 & 1859 & 1841 & 1797 \\
\hline
\end{tabular}

aThe scale factors for B3LYP and M06-2X are 0.97 and 0.94 , respectively, taken from the ratio of the calculated harmonic frequency and the experimental frequency $\left(2143 \mathrm{~cm}^{-1}\right)$ for free CO as shown in Supplementary Table 6

energetically much higher than the $\mathrm{C}_{3 \mathrm{v}} \mathrm{BFe}(\mathrm{CO})_{3}{ }^{-}$structure. Table 1 lists the calculated $\mathrm{CO}$ stretching frequencies and IR intensities of the most stable structure together with the experimental values. The agreement between theory and experiment supports the geometric and electronic structure assignments of the observed $\mathrm{BFe}(\mathrm{CO})_{3}{ }^{-}$anion complex. Unfortunately, the $\mathrm{Fe}-\mathrm{B}$ stretching frequency of $\mathrm{BFe}(\mathrm{CO})_{3}-$ cannot be directly observed as it was predicted at the B3LYP level to absorb at $863 \mathrm{~cm}^{-1}$ with very low IR intensity $\left(5 \mathrm{~km} \mathrm{~mol}^{-1}\right)$.

Geometry optimizations with DFT functionals give rise to $\mathrm{B}-\mathrm{Fe}$ distances of $1.69,1.67$, and $1.61 \AA$, respectively, at the PBE, B3LYP, and M06-2X levels. DLPNO-CCSD(T) calculation provides an equilibrium B-Fe bond distance of $1.63 \AA$ (Supplementary Fig. 7). These values are considerably shorter than the sum of the triple-bond covalent radii of iron and boron atoms proposed by Pyykkö and coworkers $(\mathrm{B}+\mathrm{Fe}=1.75 \AA)^{43}$. Such a short bond distance suggests that the $\mathrm{B}-\mathrm{Fe}$ bond in $\mathrm{BFe}(\mathrm{CO})_{3}{ }^{-}$ should have a bond order higher than three. The calculated bonding dissociation energy $\left(D_{\mathrm{e}}\right)$ is $124.6 \mathrm{kcal} \mathrm{mol}^{-1}$ at the M062X level, which also supports the assignment to a higher bond order in the complex. For comparison, three extra model molecules of $\mathrm{FBFe}(\mathrm{CO})_{3}, \mathrm{~F}_{2} \mathrm{BFe}(\mathrm{CO})_{3}{ }^{-}$, and $\mathrm{F}_{2} \mathrm{BFe}(\mathrm{CO})_{4}{ }^{-}$ complexes with triple, double, and single $\mathrm{B}-\mathrm{Fe}$ bonds were also computationally designed. Their corresponding B-Fe bond distances as well as the relaxed force constants which have been successfully applied to quantify bond strength ${ }^{44,45}$ are listed in Supplementary Table 2. The B-Fe bond length $(1.61 \AA)$ and relaxed force constant (not scaled, $481 \mathrm{~N} \mathrm{~m}^{-1}$ ) of $\mathrm{BFe}(\mathrm{CO})_{3}{ }^{-}$are shorter and larger than those of $\mathrm{FBFe}(\mathrm{CO})_{3}\left(1.81 \AA, 220 \mathrm{~N} \mathrm{~m}^{-1}\right)$, which involves a typical $\mathrm{B} \equiv \mathrm{Fe}$ triple bonding. The bond length and relaxed force constant for double-bonded $\mathrm{F}_{2} \mathrm{~B}=\mathrm{Fe}(\mathrm{CO})_{3}-$ $\left(1.94 \AA, 158 \mathrm{~N} \mathrm{~m}^{-1}\right)$ and single-bonded $\mathrm{F}_{2} \mathrm{~B}-\mathrm{Fe}(\mathrm{CO})_{4}{ }^{-}(2.02 \AA$, $140 \mathrm{~N} \mathrm{~m}^{-1}$ ) are in line with values for double and single bonds, respectively.

Figure 3 displays the canonical Kohn-Sham valence $\mathrm{B}-\mathrm{Fe}$ nonbonding (11e), bonding $\left(13 \mathrm{a}_{1}, 10 \mathrm{e}, 14 \mathrm{a}_{1}\right)$ and the corresponding antibonding orbitals $\left(17 \mathrm{a}_{1}, 12 \mathrm{e}, 15 \mathrm{a}_{1}\right)$ of $\mathrm{BFe}(\mathrm{CO})_{3}{ }^{-}$. Their atomic orbital contributions are listed in Supplementary Tables 2 and 3. The highest occupied doubly degenerate 11e MOs are largely B-Fe non-bonding in character, and are primarily $\mathrm{Fe} 3 \mathrm{~d}_{\delta}$ atomic orbitals that comprise notable Fe-to-CO $2 \pi^{*}$ backdonation interaction. The $14 \mathrm{a}_{1} \mathrm{MO}$ is a $\sigma$-type $\mathrm{B}-\mathrm{Fe}$ bonding orbital, which is composed of $28 \% \mathrm{Fe} 3 \mathrm{~d}_{\mathrm{z}}^{2}+9 \% \mathrm{Fe} 4 \mathrm{p}_{\mathrm{z}}$ and $26 \% \mathrm{~B}$ $2 \mathrm{p}_{\mathrm{z}}+23 \%$ B $2 \mathrm{~s}$. The doubly degenerate $10 \mathrm{e}$ MOs are $\pi$-type B-Fe bonding orbitals, which are formed by the interactions between Fe $3 d_{x z / y z}(68 \%)$ and B $2 \mathrm{p}_{x / y}(10 \%)$. Below these MOs, the $13 \mathrm{a}_{1}$ $\mathrm{MO}$ composed of $45 \% \mathrm{Fe} 3 \mathrm{~d}_{\mathrm{z}}^{2}+3 \% \mathrm{Fe} 4 \mathrm{p}_{\mathrm{z}}+3 \% \mathrm{Fe} 4 \mathrm{~s}$ and $40 \% \mathrm{~B}$ 


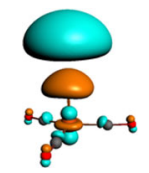

$17 \mathrm{a}_{1}$

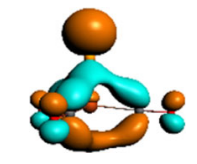

$15 a_{1}$
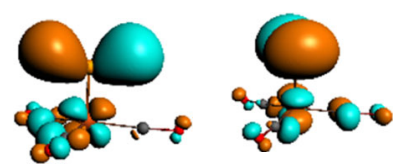

$12 e$

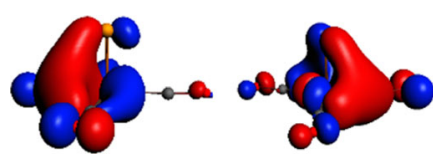

$11 \mathrm{e}$

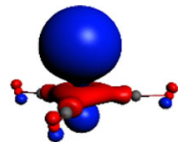

$13 \mathrm{a}_{1}$

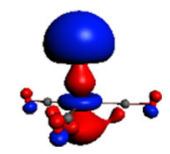

$14 \mathrm{a}_{1}$

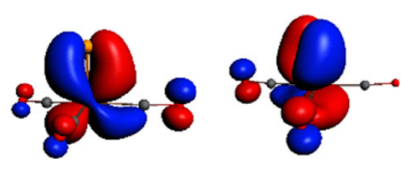

$10 e$
Fig. 3 The canonical Kohn-Sham valence molecular orbitals of $\mathrm{BFe}(\mathrm{CO})_{3}-$. The B-Fe nonbonding (11e), bonding $\left(13 a_{1}, 10 e, 14 a_{1}\right)$ and the corresponding antibonding molecular orbitals $\left(17 a_{1}, 12 e, 15 a_{1}\right)$ are plotted with isosurfaces $=$ 0.05 au

$2 \mathrm{~s}+2 \% \mathrm{~B} 2 \mathrm{p}_{\mathrm{z}}$ is another $\sigma$-type B-Fe bonding MO. The results clearly show that there are four occupied $\mathrm{MOs}$ in $\mathrm{BFe}(\mathrm{CO})_{3}{ }^{-}$, which can be identified as two $\sigma\left(14 \mathrm{a}_{1}\right.$ and $13 \mathrm{a}_{1}$, hereafter $\sigma_{\mathrm{p}}$ and $\sigma_{\mathrm{s}}$ respectively) and two $\pi(10 \mathrm{e}) \mathrm{B}-\mathrm{Fe}$ bonding interactions. The $\mathrm{B} \equiv \mathrm{Fe}$ quadruple bonding assignment is also supported by adaptive natural density partitioning (AdNDP) ${ }^{46}$ analyses shown in Supplementary Table 2. The semi-localized results indicate that the $\mathrm{B}-\mathrm{Fe}$ bonding interactions in $\mathrm{BFe}(\mathrm{CO})_{3}{ }^{-}$involve two $5 \mathrm{c}-2 \mathrm{e} \sigma$ bonds and two $5 \mathrm{c}-2 \mathrm{e} \pi$ bonds. It should be mentioned that here there is some mixing of the $\mathrm{B}-\mathrm{Fe}$ and $\mathrm{Fe}-\mathrm{CO}$ bonding MOs, but the major components and shapes of MOs resemble those of the classical electron-pair bonding models. The above bonding analysis also indicates that the $\mathrm{B}-\mathrm{Fe}$ bonding interactions have quite small effect on the Fe-to-CO $2 \pi^{*}$ back-donation interactions in the $\mathrm{Fe}(\mathrm{CO})_{3}{ }^{-}$fragment. Charge analyses in Supplementary Table 4 also indicate that the negative charge is largely located on the $\mathrm{Fe}(\mathrm{CO})_{3}$ moiety. The antisymmetric $\mathrm{CO}$ stretching frequency $\left(1841 \mathrm{~cm}^{-1}\right)$ of $\mathrm{BFe}(\mathrm{CO})_{3}{ }^{-}$is only slightly higher than that of free $\mathrm{Fe}(\mathrm{CO})_{3}{ }^{-}\left(1780 \mathrm{~cm}^{-1}\right)$, but is lower than those of neutral $\mathrm{Fe}$ $(\mathrm{CO})_{4}$ and $\mathrm{Fe}(\mathrm{CO})_{5}$.

Figure 4 qualitatively illustrates the bonding picture of $\mathrm{BFe}$ $(\mathrm{CO})_{3}{ }^{-}$and its correlation to the interacting fragments $\mathrm{B}$ and $\mathrm{Fe}$ $(\mathrm{CO})_{3}{ }^{-}$. The major interactions between $\mathrm{B}$ and $\mathrm{Fe}(\mathrm{CO})_{3}{ }^{-}$involve one $\sigma_{\mathrm{p}}$-type $\left(14 \mathrm{a}_{1}\right) \mathrm{Fe}-\mathrm{B}$ electron-sharing bonding, two degenerate $\pi$-type $(10 \mathrm{e}) \mathrm{Fe} \rightarrow \mathrm{B}$ dative bonding, and one $\sigma_{\mathrm{s}}$-type $\left(13 \mathrm{a}_{1}\right)$ $\mathrm{B} \rightarrow \mathrm{Fe}$ dative bonding, leading to the aforementioned quadruple bonding. The ground state $\mathrm{BFe}(\mathrm{CO})_{3}{ }^{-}$anion can thus be regarded as being formed via the interactions between the ground state ${ }^{2} \mathrm{P}-\mathrm{B}$ atom with the $(2 \mathrm{~s})^{2}\left(2 \mathrm{p}_{\mathrm{z}}\right)^{1}$ configuration and the $\mathrm{Fe}$ $(\mathrm{CO})_{3}{ }^{-}$fragment in its ${ }^{2} \mathrm{~A}_{1}$ electronic ground state with $\left(\mathrm{a}_{1}\right)^{1}(\mathrm{e})^{4}$ $(\mathrm{e})^{4}$ configuration. The $\mathrm{B} \equiv \mathrm{Fe}$ quadruple bonding interactions are further characterized using the principal interacting orbital (PIO) approach ${ }^{47}$. The calculated PIOs and PIMOs shown in Supplementary Figs. 8-11 clearly reveal the fourfold bonding interactions between $\mathrm{B}$ and $\mathrm{Fe}$ in the $\mathrm{BFe}(\mathrm{CO})_{3}{ }^{-}$anion, which further support the above assignment.

The strengths of the above-mentioned pairwise orbital interactions can be quantitatively estimated by the EDA-NOCV method $^{48,49}$. The numerical results calculated at the M06-2X/ TZ2P level are listed in Supplementary Table 5. The EDA-NOCV calculations suggest that $43 \%$ of the attractive forces in $\mathrm{BFe}$ $(\mathrm{CO})_{3}{ }^{-}$are due to orbital (covalent) interactions. The breakdown

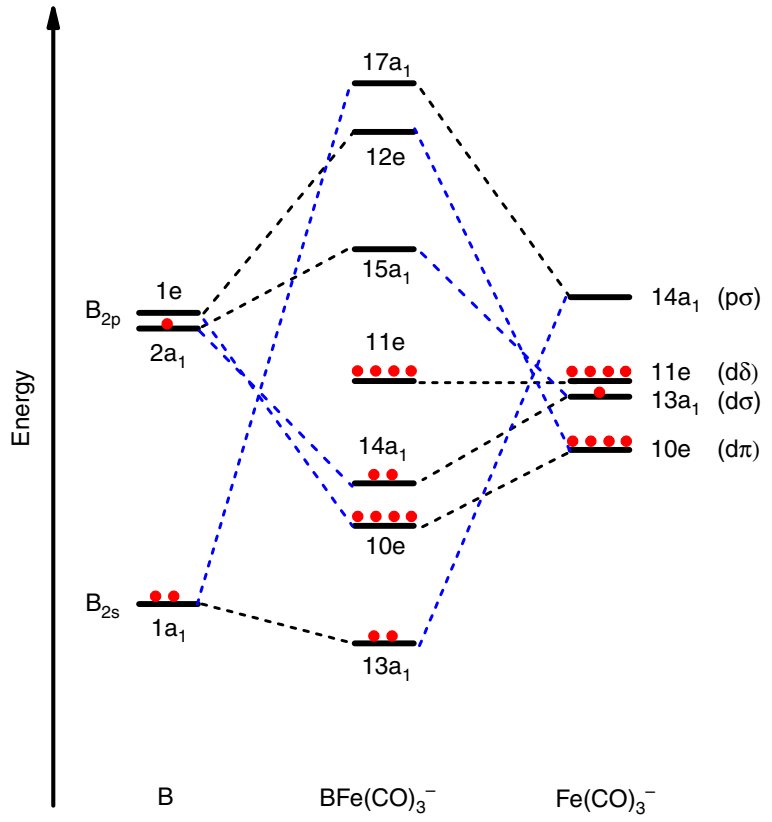

Fig. 4 Bonding scheme of the $C_{3 v}$ structure of ${ }^{1} A_{1}-B F e(C O)_{3}-$. The scheme qualitatively illustrates the bonding interactions between boron $2 \mathrm{~s}-2 \mathrm{p}$ orbitals and $\mathrm{Fe} 3 \mathrm{~d} / 4 \mathrm{p}$ orbitals in the $\mathrm{Fe}(\mathrm{CO})_{3}{ }^{-}$fragment

of the orbital interaction term $\Delta E_{\text {orb }}$ into individual orbital contributions reveals that the four bonding components contribute $42.8 \%\left(\sigma_{\mathrm{p}}\right), 46.6 \%$ (two $\pi$ ), and $8.2 \%\left(\sigma_{\mathrm{s}}\right)$ of the orbital bonding interactions. Although the fourth component $\left(\sigma_{\mathrm{s}} \mathrm{B} \rightarrow \mathrm{Fe}\right.$ dative bonding interaction) is much weaker than the electronsharing $\sigma_{\mathrm{p}}$ and two $\mathrm{Fe} \rightarrow \mathrm{B}$ dative $\pi$ bonding interactions, it has a calculated interaction energy of $18.4 \mathrm{kcal} / \mathrm{mol}$, indicating that it is a non-negligible, albeit weak, bonding interaction. The deformation densities $\Delta \rho(\sigma)$ and $\Delta \rho(\pi)$ that are connected to the $\sigma$ and $\pi$ interactions in $\mathrm{BFe}(\mathrm{CO})_{3}{ }^{-}$are displayed in Supplementary Table 5. The deformation densities $\Delta \rho$ show the direction of the charge flow and the orbitals that are involved, where the color code of the charge flow is red $\rightarrow$ blue. The results clearly indicate the electron-sharing bonding nature of the stronger $\sigma_{\mathrm{p}}$ interaction and the dative bonding character of the two $\pi$ and the weaker $\sigma_{\mathrm{s}}$ interactions. The weaker $\sigma_{\mathrm{s}}$ interaction is strongly polarized with obvious charge flow from $\mathrm{B}$ atom to $\mathrm{Fe}(\mathrm{CO})_{3}{ }^{-}$. In contrast, the two degenerate $\pi$ interactions show reversed charge flow from $\mathrm{Fe}$ $(\mathrm{CO})_{3}{ }^{-}$to $\mathrm{B}$.

To make certain that these single-configuration quantum chemical methods are reliable, the wavefunction of $\mathrm{BFe}(\mathrm{CO})_{3}{ }^{-}$is further examined in a multi-configurational framework. Ab initio CASSCF calculation involving 12 valence electrons in a space of 12 MOs was performed at the M06-2X optimized geometry, and the Löwdin natural orbitals (NOs) were analyzed using the CASSCF density matrix. The six strongly occupied and six weakly occupied natural orbitals and their occupation numbers (NOONs) are displayed in Supplementary Fig. 12. There is no significant occupation number of $\mathrm{B}-\mathrm{Fe}$ antibonding NOs, $1 \sigma^{\star 0.05} \pi^{\star 0.18} 2 \sigma^{\star 0.11}$, indicating that the multi-reference feature of this molecule is not very large. The $\mathrm{B} \equiv \mathrm{Fe}$ effective bond order $(\mathrm{EBO})^{9}$ based on the ground-state CASSCF wavefunctions is calculated as 3.7, which is rather close to four and further supports the $\mathrm{B} \equiv \mathrm{Fe}$ quadruple bonding assignment.

In summary, the $\mathrm{BFe}(\mathrm{CO})_{3}{ }^{-}$anion complex has been identified by a combined quantum chemical and experimental study. The anion is generated in the gas phase and is studied by massselected infrared photodissociation spectroscopy. The complex 
has been characterized to have a cylindrical $\mathrm{BFe}(\mathrm{CO})_{3}{ }^{-}$structure with $C_{3 \mathrm{v}}$ symmetry and a very short $\mathrm{B}-\mathrm{Fe}$ bond distance. Electronic structure and chemical bonding analyses indicate that the complex exhibits an unprecedented $\mathrm{B} \equiv \mathrm{Fe}$ quadruple bonding interactions, featuring one electron-sharing $\sigma$ bond, two $\mathrm{Fe} \rightarrow \mathrm{B}$ dative $\pi$ bonds as well as one additional weak $\mathrm{B} \rightarrow \mathrm{Fe}$ dative $\sigma$ bonding interaction. The results extend the maximum bond order of boron element to four. This study reveals that a variety of such quadruple-bonded systems of main-group and transition-metal elements may exist in inorganic and organometallic chemistry.

\section{Methods}

Experimental details. The anion complexes were generated in the gas phase using a pulsed laser vaporization/supersonic expansion ion source. A bulk target compressed from an isotopically enriched $\left({ }^{11} \mathrm{~B}\right.$ - or ${ }^{10} \mathrm{~B}$-depleted) or natural abundance boron powder was used. The ions were produced from the laser vaporization process in expansions of helium seeded with $5-10 \%$ CO using a pulsed valve (General Valve, Series 9) at 0.5-1.0 MPa backing pressure. After free expansion and cooling, the anions were skimmed into a second chamber where they were pulse-extracted into a Wiley-McLaren type time-of-flight mass spectrometer. The anions of interest were mass-selected and decelerated into the extraction region of a second collinear time-of-flight mass spectrometer, where they were dissociated by a tunable IR laser. The tunable IR laser used is generated by a KTP/KTA//AgGaSe2 optical parametric oscillator/amplifier system (OPO/OPA, Laser Vision) pumped by a Nd: YAG laser, producing about $0.5-1.0 \mathrm{~mJ}$ per pulse in the range of 1600 $-2200 \mathrm{~cm}^{-1}$. Resonant absorption leads to fragmentation of the anion complex. The infrared photodissociation spectrum is obtained by monitoring the yield of the fragment anion as a function of the dissociation IR laser wavelength and normalizing to parent anion signal.

Computational methods. Geometry optimization and vibrational frequency calculations of the most stable structure of $\mathrm{BFe}(\mathrm{CO})_{3}{ }^{-}$were performed using the density functional theory (DFT) methods with the $\mathrm{PBE}^{50,51}$, B3LYP ${ }^{52,53}$, and M06$2 \mathrm{X}^{54}$ functionals using the ADF 2016 program packages [ADF 2016.101, http:// www.scm.com]. The Slater-type-orbital (STO) basis sets with the quality of triple- $\zeta$ plus two polarization functions (TZ2P) $)^{55}$ were applied with the consideration of scalar-relativistic (SR) effects at the zero-order regular approximation (ZORA) ${ }^{56}$. In order to obtain more accurate B-Fe bond distance, a series of single-point calculations at different B-Fe distances were carried out using a domain-based local pair natural orbital coupled cluster method, DLPNO-CCSD $(T)^{57-59}$, with the def2TZVP basis sets (11s6p2d1f)/[5s3p2d1f] for the B, C and O, and (17s11p7d1f)/ $[6 s 4 \mathrm{p} 4 \mathrm{~d} 1 \mathrm{f}]$ for $\mathrm{Fe}^{60}$. The DLPNO-CCSD(T) calculations were performed with the ORCA program package ${ }^{61}$.

The chemical bonding properties were analysed by employing several different methods including adaptive natural density partitioning (AdNDP) ${ }^{46}$ and the principal interacting orbital (PIO) ${ }^{47}$. The def2-TZVP basis sets, (11s6p2d1f)/ [5s3p2d1f] for the B, C, and O, and (17s11p7d1f)/[6s4p4d1f] for Fe in Gaussian 09 program $^{62}$, were applied in the AdNDP calculations. For determining the most stable structure of $\mathrm{BFe}(\mathrm{CO})_{3}{ }^{-}, \mathrm{BFe}(\mathrm{CO})_{4}{ }^{-}$, and $\mathrm{BFe}(\mathrm{CO})_{5}{ }^{-}$, $\mathrm{B} 3 \mathrm{LYP}$ with Dunning's correlation consistent basis sets aug-cc-pVTZ ${ }^{63},(10 \mathrm{~s} 5 \mathrm{p} 2 \mathrm{~d} 1 \mathrm{f}) /[4 \mathrm{~s} 3 \mathrm{p} 2 \mathrm{~d} 1 \mathrm{f}]$ for B, C, and O, and (20s16p8d2flg)/[7s6p4d2flg] for $\mathrm{Fe}^{64}$ were applied with Gaussian 09 program. The PIO analyses were also carried out using the Gaussian 09 program with aug-cc-pVTZ basis sets.

The multi-configurational complete-active-space SCF (CASSCF) ${ }^{65}$ calculations were performed using the MOLPRO 2012.1 program package to examine the description of electronic configurations based on the DFT-optimized geometries with the Dunning's correlation consistent basis sets aug-cc-pVTZ ${ }^{63}$, (10s5p2d1f)/ [4s3p2d1f] for B, C, and O, and (20s16p8d2f1g)/[7s6p4d2f1g] for $\mathrm{Fe}^{64}$. The active space used 12 valence electrons in 12 orbitals $\left(12_{e}, 12_{o}\right)$, which includes six occupied orbitals and six unoccupied orbitals at the frontier region of the molecular orbitals.

\section{Data availability}

The data that support the findings of this study are available within the article and the associated Supplementary Data. Any other data are available from the corresponding author upon request.

Received: 28 June 2019; Accepted: 25 September 2019; Published online: 17 October 2019

\section{References}

1. Cotton, F. A. et al. Mononuclear and polynuclear chemistry of rhenium (III): its pronounced homophilicity. Science 145, 1305-1307 (1964).
2. Cotton, F. A. Metal-metal bonding in $\left[\mathrm{Re}_{2} \mathrm{X}_{8}\right]^{2-}$ ions and other metal atom clusters. Inorg. Chem. 4, 334-336 (1965).

3. Cotton, F. A., Murillo, C. A. \& Walton, R. A. Multiple bonds between metal atoms. (Springer Science \& Business Media, 2005).

4. Chisholm, M. H. \& Macintosh, A. M. Linking multiple bonds between metal atoms: clusters, dimers of "dimers", and higher ordered assemblies. Chem. Rev. 105, 2949-2976 (2005).

5. Nguyen, T. et al. Synthesis of a stable compound with fivefold bonding between two chromium (I) centers. Science 310, 844-847 (2005).

6. Frenking, G. Building a quintuple bond. Science 310, 796-797 (2005).

7. Wagner, F. R., Noor, A. \& Kempe, R. Ultrashort metal-metal distances and extreme bond orders. Nat. Chem. 1, 529-536 (2009).

8. Tsai, Y.-C. \& Chang, C.-C. Recent progress in the chemistry of quintuple bonds. Chem. Lett. 38, 1122-1129 (2009).

9. Roos, B. O., Borin, A. C. \& Gagliardi, L. Reaching the maximum multiplicity of the covalent chemical bond. Angew. Chem. Int. Ed. 46, 1469-1472 (2007).

10. Frenking, G. \& Tonner, R. Theoretical chemistry: the six-bond bound. Nature 446, 276-277 (2007).

11. Weinhold, F. \& Landis, C. R. High bond orders in metal-metal bonding. Science 316, 61-63 (2007).

12. Collman, J. P. \& Boulatov, R. Heterodinuclear transition-metal complexes with multiple metal-metal bonds. Angew. Chem. Int. Ed. 41, 3948-3961 (2002).

13. Eisenhart, R. J., Clouston, L. J. \& Lu, C. C. Configuring bonds between firstrow transition metals. Acc. Chem. Res. 48, 2885-2894 (2015).

14. Falvello, L. R., Foxman, B. M. \& Murillo, C. A. Fitting the pieces of the puzzle: the $\delta$ bond. Inorg. Chem. 53, 9441-9456 (2014).

15. Lyngdoh, R. H. D., Schaefer, H. F. III \& King, R. B. Metal-metal (MM) bond distances and bond orders in binuclear metal complexes of the first row transition metals titanium through zinc. Chem. Rev. 118, 11626-11706 (2018).

16. Gagliardi, L. \& Roos, B. O. Quantum chemical calculations show that the uranium molecule $U_{2}$ has a quintuple bond. Nature 433, 848-851 (2005).

17. Knecht, S., Jensen, H. J. A. \& Saue, T. Relativistic quantum chemical calculations show that the uranium molecule $\mathrm{U}_{2}$ has a quadruple bond. Nat. Chem. 11, 40-44 (2019).

18. Hu, H. S. \& Kaltsoyannis, N. The shortest Th-Th distance from a new type of quadruple bond. Phys. Chem. Chem. Phys. 19, 5070-5076 (2017).

19. Fischer, R. C. \& Power, P. P. $\pi$-bonding and the lone pair effect in multiple bonds involving heavier main group elements: developments in the new millennium. Chem. Rev. 110, 3877-3923 (2010).

20. Zhou, M. F. et al. OCBBCO: a neutral molecule with some boron-boron triple bond character. J. Am. Chem. Soc. 124, 12936-12937 (2002).

21. Li, S. D., Zhai, H. J. \& Wang, L. S. $\mathrm{B}_{2}(\mathrm{BO})_{2}{ }^{2-}$ - diboronyl diborene: a linear molecule with a triple boron-boron bond. J. Am. Chem. Soc. 130, 2573-2579 (2008).

22. Braunschweig, $H$. et al. Ambient-temperature isolation of a compound with a boron-boron triple bond. Science 336, 1420-1422 (2012).

23. Frenking, G. \& Holzmann, N. A boron-boron triple bond. Science 336, 1394-1395 (2012).

24. Zhang, $\mathrm{X}$. X. et al. Realization of an $\mathrm{Al} \equiv \mathrm{Al}$ triple bond in the gas-phase $\mathrm{Na}_{3} \mathrm{Al}_{2}{ }^{-}$cluster via double electronic transmutation. Angew. Chem. Int. Ed. 57, 14060-14064 (2018).

25. Sekiguchi, A., Kinjo, R. \& Ichinohe, M. A stable compound containing a silicon-silicon triple bond. Science 305, 1755-1757 (2004).

26. Stender, M., Phillips, A. D., Wright, R. J. \& Power, P. P. Synthesis and characterization of a digermanium analogue of an alkyne. Angew. Chem. Int. Ed. 41, 1785-1787 (2002).

27. Shaik, S. et al. Quadruple bonding in $\mathrm{C}_{2}$ and analogous eight-valence electron species. Nat. Chem. 4, 195-200 (2012).

28. Shaik, S., Rzepa, H. S. \& Hoffmann, R. One molecule, two atoms, three views, four bonds? Angew. Chem. Int. Ed. 52, 3020-3033 (2013).

29. Markus, H. \& Frenking, G. The chemical bond in $C_{2}$. Chem. Eur. J. 22, $4100-4108$ (2016).

30. Xu, L. T. \& Dunning, T. H. Jr Insights into the perplexing nature of the bonding in $\mathrm{C}_{2}$ from generalized valence bond calculations. J. Chem. Theory Comput. 10, 195-201 (2014).

31. Hu, H.-S., Qiu, Y.-H., Xiong, X.-G., Schwarz, W. E. \& Li, J. On the maximum bond multiplicity of carbon: unusual $\mathrm{C} \equiv \mathrm{U}$ quadruple bonding in molecular CUO. Chem. Sci. 3, 2786-1796 (2012).

32. Qiu, Y. H., Hu, H. S. \& Li, J. Quadruple bonding of carbon in terminal carbides. Sci. China Chem. 57, 426-434 (2014).

33. Papakondylis, A., Miliordos, E. \& Mavridis, A. Carbonyl boron and related systems: An ab initio study of $\mathrm{B}-\mathrm{X}$ and $\mathrm{YB} \equiv \mathrm{BY}\left({ }^{1} \Sigma_{\mathrm{g}}{ }^{+}\right)$, where $\mathrm{X}=\mathrm{He}, \mathrm{Ne}, \mathrm{Ar}$, $\mathrm{Kr}, \mathrm{CO}, \mathrm{CS}, \mathrm{N}_{2}$ and $\mathrm{Y}=\mathrm{Ar}, \mathrm{Kr}, \mathrm{CO}, \mathrm{CS}, \mathrm{N}_{2}$. J. Phys. Chem. A 108, 4335-4340 (2004).

34. Ducati, L. C., Takagi, N. \& Frenking, G. Molecules with all triple bonds: OCBBCO, $\mathrm{N}_{2} \mathrm{BBN}_{2}$, and $[\mathrm{OBBBBO}]_{2}^{-}$. J. Phys. Chem. A 113, 11693-11698 (2009). 
35. Mitoraj, M. P. \& Michalak, A. Multiple boron-boron bonds in neutral molecules: an insight from the extended transition state method and the natural orbitals for chemical valence scheme. Inorg. Chem. 50, 2168-2174 (2011).

36. Braunschweig, H. \& Colling, M. Transition metal complexes of boronsynthesis, structure and reactivity. Coord. Chem. Rev. 223, 1-51 (2001).

37. Braunschweig, H., Kollann, C. \& Rais, D. Transition-metal complexes of boron-new insights and novel coordination modes. Angew. Chem. Int. Ed. 45, 5254-5274 (2006).

38. Wang, X. F., Roos, B. O. \& Andrews, L. Calculations and matrix infrared spectra of terminal borylene complexes $\mathrm{FB}=\mathrm{MF}_{2}$. Angew. Chem. Int. Ed. 49, 157-160 (2010).

39. Tzelia, D. \& Mavridisb, A. Electronic structure and bonding of the $3 \mathrm{~d}$ transition metal borides, $\mathrm{MB}, \mathrm{M}=\mathrm{Sc}, \mathrm{Ti}, \mathrm{V}, \mathrm{Cr}, \mathrm{Mn}, \mathrm{Fe}, \mathrm{Co}, \mathrm{Ni}$, and $\mathrm{Cu}$ through all electron ab initio calculations. J. Chem. Phys. 128, 034309 (2008).

40. Borin, A. C. \& Gobbo, J. P. Low-lying singlet and triplet electronic states of RhB. J. Phys. Chem. A. 112, 4394-4398 (2008).

41. Jian, T., Cheung, L. F., Chen, T. T. \& Wang, L. S. Bismuth-boron multiple bonding in $\mathrm{BiB}_{2} \mathrm{O}^{-}$and $\mathrm{Bi}_{2} \mathrm{~B}^{-}$. Angew. Chem. Int. Ed. 56, 9551-9555 (2017).

42. Wang, G., Chi, C., Xing, X., Ding, C. \& Zhou, M. A collinear tandem time-offlight mass spectrometer for infrared photodissociation spectroscopy of massselected ions. Sci. China Chem. 57, 172-177 (2014).

43. Pyykkö, P., Riedel, S. \& Patzschke, M. Triple-bond covalent radii. Chem. Eur. J. 11, 3511-3520 (2005).

44. Brandhorst, K. \& Grunenberg, J. Characterizing chemical bond strengths using generalized compliance constants. ChemPhysChem 8, 1151-1156 (2007).

45. Brandhorst, K. \& Grunenberg, J. How strong is it? The interpretation of force and compliance constants as bond strength descriptors. Chem. Soc. Rev. 37, 1558-1567 (2008).

46. Zubarev, D. Y. \& Boldyrev, A. I. Developing paradigms of chemical bonding: adaptive natural density partitioning. Phys. Chem. Chem. Phys. 10, 5207-5217 (2008).

47. Zhang, J. X., Sheong, F. K. \& Lin, Z. Y. Unravelling chemical interactions with principal interacting orbital analysis. Chem. Eur. J. 24, 9639-9650 (2018).

48. Michalak, A., Mitoraj, M. \& Ziegler, T. Bond orbitals from chemical valence theory. J. Phys. Chem. A 112, 1933-1939 (2008).

49. Mitoraj, M. P., Michalak, A. \& Ziegler, T. A combined charge and energy decomposition scheme for bond analysis. J. Chem. Theory Comput. 5, 962-975 (2009).

50. Ernzerhof, M. \& Scuseria, G. E. Assessment of the Perdew-Burke-Ernzerhof exchange-correlation functional. J. Chem. Phys. 110, 5029-5036 (1999).

51. Hammer, B., Hansen, L. B. \& Nørskov, J. K. Improved adsorption energetics within density-functional theory using revised Perdew-Burke-Ernzerhof functionals. Phys. Rev. B 59, 7413 (1999).

52. Becke, A. D. Density functional thermochemistry. III. The role of exact exchange. J. Chem. Phys. 98, 5648-5652 (1993).

53. Lee, C., Yang, W. \& Parr, R. G. Development of the Colle-Salvetti correlationenergy formula into a functional of the electron density. Phys. Rev. B 37, 785789 (1988).

54. Zhao, Y. \& Truhlar, D. G. The M06 suite of density functionals for main group thermochemistry, thermochemical kinetics, noncovalent interactions, excited states, and transition elements: two new functionals and systematic testing of four M06-class functionals and 12 other functionals. Theor. Chem. Acc. 120, 215-241 (2008).

55. van Lenthe, E. \& Baerends, E. J. Optimized Slater-type basis sets for the elements 1-118. J. Comput. Chem. 24, 1142-1156 (2003).

56. van Lenthe, E., Baerends, E.-J. \& Snijders, J. G. Relativistic regular twocomponent Hamiltonians. J. Chem. Phys. 99, 4597-4610 (1993).

57. Riplinger, C. \& Neese, F. An efficient and near linear scaling pair natural orbital based local coupled cluster method. J. Chem. Phys. 138, 034106 (2013).

58. Riplinger, C., Pinski, P., Becker, U., Valeev, E. F. \& Neese, F. Sparse maps-A systematic infrastructure for reduced-scaling electronic structure methods. II. Linear scaling domain based pair natural orbital coupled cluster theory. J. Chem. Phys. 144, 024109 (2016).

59. Riplinger, C., Sandhoefer, B., Hansen, A. \& Neese, F. Natural triple excitations in local coupled cluster calculations with pair natural orbitals. J. Chem. Phys. 139, 134101 (2013).
60. Schäfer, A., Huber, C. \& Ahlrichs, R. Fully optimized contracted Gaussian basis sets of triple zeta valence quality for atoms Li to Kr. J. Chem. Phys. 100, 5829-5835 (1994)

61. Neese, F. The ORCA program system. WIREs Comput. Mol. Sci. 2, 73-78 (2012).

62. Frisch, M. J. et al. Gaussian 09, Revision C.01. (Gaussian, Inc., Wallingford CT, 2009).

63. Dunning, T. H. Jr Gaussian basis sets for use in correlated molecular calculations. I. The atoms boron through neon and hydrogen. J. Chem. Phys. 90, 1007-1023 (1989)

64. Balabanov, N. B. \& Peterson, K. A. Systematically convergent basis sets for transition metals. I. All-electron correlation consistent basis sets for the $3 \mathrm{~d}$ elements Sc-Zn. J. Chem. Phys. 123, 064107 (2005)

65. Celani, P. \& Werner, H.-J. Multireference perturbation theory for large restricted and selected active space reference wave functions. J. Chem. Phys. 112, 5546-5557 (2000).

\section{Acknowledgements}

This work was supported by National Natural Science Foundation of China (grant nos 21433005, 21688102, 21590792, and 91426302). The calculations were done using supercomputers at the Southern University of Science and Technology (SUSTech) and Tsinghua National Laboratory for Information Science and Technology.

\section{Author contributions}

The experiments were performed at East China University of Technology by C.C., L.M. and M.L. The theoretical calculations were performed at Tsinghua University by J.W., Y.Z. and W.L. M.Z., H.H. and J.L. wrote the paper and supervised the experimental and theoretical parts. All authors discussed the results and commented on the manuscript at all stages.

\section{Competing interests}

The authors declare no competing interests.

\section{Additional information}

Supplementary information is available for this paper at https://doi.org/10.1038/s41467 019-12767-5.

Correspondence and requests for materials should be addressed to H.-S.H., M.Z. or J.L.

Peer review information Nature Communications thanks Julien Eng, Jana Roithová and the other, anonymous, reviewer for their contribution to the peer review of this work. Peer reviewer reports are available.

Reprints and permission information is available at http://www.nature.com/reprints

Publisher's note Springer Nature remains neutral with regard to jurisdictional claims in published maps and institutional affiliations.

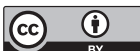

Open Access This article is licensed under a Creative Common Attribution 4.0 International License, which permits use, sharing, adaptation, distribution and reproduction in any medium or format, as long as you give appropriate credit to the original author(s) and the source, provide a link to the Creative Commons license, and indicate if changes were made. The images or other third party material in this article are included in the article's Creative Commons license, unles indicated otherwise in a credit line to the material. If material is not included in the article's Creative Commons license and your intended use is not permitted by statutory regulation or exceeds the permitted use, you will need to obtain permission directly from the copyright holder. To view a copy of this license, visit http://creativecommons.org/ licenses/by/4.0/

(c) The Author(s) 2019 